\title{
CUIDADOS ESPECIAIS COM O POLITRAUMATIZADO
}

\author{
Gaspar Soares Brandão, \\ Professor Titular de Prótese e Trau- \\ matologia Maxilo-Faciais.
}

\section{SINOPSE}

A partir de conceitos gerais, são revistas as condições de atendimento do politraumatizado, nas várias etapas dos cuidados gerais e locais. Cuidados e indicações com os pacientes nas diversas fases em que sob o ponto de vista didático é desenvolvido o tema. É realizada revisão sôbre os exames clínicos, laboratoriais e as atenções a dispensar no transporte dos feridos.

Trauma, ferida resultante da ação de agente vulnerante externo sôbre o organismo vivo $\left({ }^{4}\right)$. As fraturas são consideradas como traumas (feridas), pois nada mais representam que a solução de continuidade de tecido. À associação de ferida e fratura denominamos lesão.

Os agentes traumáticos são divididos em: mecânicos, físicos, químicos, cada qual gerando a típica vulneração que varia segundo volume, velocidade, característica exterior (forma), área que atinge a situação do lesado. A êstes devemos agregar, segundo conceitos mais modernos, os agentes psíquicos, que podem produzir agressões com características variáveis. Feridas da psique, neuroses ou psicopatias, as lesões deixaram de ser somáticas para serem catalogadas como psicossomáticas $(4,11)$.

Poderíamos conceituar ainda poli que significa muito grande quantidade e izar, desinência verbal que tem sentido imitativo e às vêzes empregado como equivalente ao sufixo ficar, que indica ou significa fazer, tornar ou ser causada... traumatizar, traumatizado $\left({ }^{3}\right)$. De conseqüência, politraumatizado é o indivíduo que sofreu múltiplos traumas, feridas e fraturas, lesões associadas à rupturas viscerais ou comprometimento

(Parte integrante do simpósio sôbre Traumatologia Maxilo-Facial realizado no $1^{\circ}$ Congresso de Patologia e Cirurgia Buco-Facial, em Fortaleza à 23/29 de novembro de 1969).

R. Fac. Odont. P. A. 10/11： 127-132, 1968/1969 
de sistemas, em decorrência e razão da intensidade, qualidade e demais características de ação e do agente vulnerante. Alguns especialistas consideram necessária a diferenciação entre politraumatizado, aquêle que padece ou sofreu muitos traumas (lesões) e politraumatismo, isto é, inúmeras desordens orgânicas que decorrem ou estão associadas a um trauma, qúe pode ser único e ao qual estão associadas várias situações colaterais anômalas de ordem geral ou local, como dôr, edema, hematoma, contusão, ferida contusa, hemorragia, perturbação da visão e ou psíquica, choque, etc., isto porque, insistimos, estas alterações decorrem de um fenômeno central e maior e dêle derivam ou a êle estão associa$\operatorname{das}(2,4,6,7,9,10,12)$.

CUIDADOS ESPECIAIS: Antes de qualquer outra atividade, diagnóstico sumário e imediato para avaliação das condições e a tomada das providências emergentes ou urgentes, deverá ser realizado.

A prioridade absoluta é a garantia da vida, pela ação rápida e com pleno conhecimento de causa e delicadeza; não deverá ser esquecido o confôrto e encorajamento do paciente, a vítima sempre espera do socorrista alivio e resguardo do seu bem supremo, a vida.

A presença de espírito e o poder de decisão rápida e correta é uma imprescindívèl atitude nos primeiros socorros. De relance sinais evidentes podem alertar para situações vitais como: cianose - asfixia; palidez, descoloramento das mucosas - hemorragia interna com anemia aguda; palidez, ansiedade - choque; cianose e respiração estertorante - lesões toraco-pulmonares, etc.

Os traumatizados inconscientes ou em estado de coma devem em princípio ser suspeitados de fraturas do crâneo. A posição e alinhamento dos membros, bem como alongamento, aplanamento ou afundamento da face, podem sugerir de imediato fraturas ou luxações dos membros ou da estrutura facial. Diagnóstico mais preciso e cuidadoso, precedido dos exames complementares será realizado no hospital. O atendimento no local do acidente tem como primeiro objetivo garantir a vida do ferido e facilitar o transporte sem agravar os padecimentos ou lesões, antes propiciando desde logo alívio e os socorros mais prementes.

Emergência - urgência. Entendemos como emergência as medidas ou intervenções necessárias a garantir a vida do paciente, criando de conseqüência oportunidade de prestar realmente o socorro necessário e urgência todos os métodos terapêuticos e intervenções que requeira o caso, com vistas a restringir os males, evitar o agravamento das lesões preparando o paciente para a etapa seguinte, tratamento definitivo.

As classificacões de qualquer ordem, inclusive as didáticas, comportam exceções que nem por isso invalidam a proposição, por exemplo: a desobstrução das vias aéreas superiores em pacientes portadores de corpo estranho na traquéia ou bronquios, será ao mesmo tempo a emergente, urgente e definitiva, pois eliminada a causa cessam os efeitos. As exceções existem e sempre existirão, por isso mesmo não vemos razão pa- 
ra, por puro amor a controvérsia, omitir as classificações ou tipificações que facilitam a transmissão da informação e a comunicação.

Os tratadistas de ,cirurgia de urgência classificam o atendimento do politraumatizado, como de resto os lesados em geral, em três faixas perfeitamente distintas $(1,2,7,8,9,10,11,13)$.

1. atendimento provisório no loeal da ocorrência, que inclui o transporte do ferido até a ambulância e nesta até o centro de atendimento primário;

2. atendimento provisório HOSPITALAR;

3. atendimento definitivo, em ambiente hospitalar e em dois níveis, geral e especializado, isto é, cada setor ou uma especialidade o atenderá por vez, verbi gratia, neurologia, cirurgia geral, oftalmologia, traumatologia ou ortopedia, sem que se guarde esta ordenação, ressalvada necessàriamente a posição da neurologia.

Os cirurgiões-dentistas, normalmente, não têm ação de qualquer ordem no atendimento provisório local ou hospitalar, a sua ação está siìuada em nível de atendimento definitivo, hospitalar, ou ambulatorial. Fiéis no entanto à ordem que recebemos, relatar o tema, cuidados especiais com o politraumatizado, parte integrante do simpósio sôbre traumatologia, apresentamos considerações que esperamos sejam úteis e atinjam o alvo desejado pelos organizadores do Congresso.

$\mathrm{Na}$ primeira fase - tratamento provisório no local - incluídos os cuidados já referidos anteriormento no comentário geral, serão desenvol- vidas atividades tais como:

a) garantia da permeabilidade das vias aéreas superiores, com desobstrução ou inclusive aplicando a respiração forçada (artificial);

b) aplicação de sedativos, tendo o cuidado na escolha para evitar problemas como: a coma e perda dos reflexos; autores há que proscrevem a morfina e seus derivados pelos riscos que podem trazer, ocasionando depressão do sistema nervoso central;

c) detenção de hemorragia pelo processo mais rápido e eficiente, quase sempre o mais simples de evitar a efusão de sangue;

d) imobilização provisória, quando couber e contribuir para facilitar o transporte;

e) curativo oclusivo, em alguns casos;

f) administração de plasma, nas grandes perdas sangüíneas;

g) em alguns casos especiais, medida particular, como traqueotomia de urgência, etc.

TRANSPORTE - O paciente será preparado e transportado com todo o cuidado e em condições especiais, segundo cada caso, pois êste quando feito imperitamente pode apressar ou levar à morte o traumatizado; muitos pensam que isto não possa ocorrer, sendo talvez importante transportar urgentemente ao invés de atender devidamente o traumatizado para transporte a menor risco. Ordinàriamente os pacientes são transportados em posição horizontal, decúbito dorsal; nos casos de lesões faciais graves - politraumatizados - a posição não é indicada, poderá haver obstrução das vias aéreas su- 
periores por muco, sangue, queda da língua no ístimo das fauces, nas fraturas bi-laterais e anteriores do corpo do mandibular $(7,8,9,11$ e 13).

Autor famoso (Keneth Lewis) apresenta a situação de maneira altamente ilustrativa, quando afirma que o paciente que é transportado olhando para o céu, mais cedo lá chegará: versão e adaptação pessoal. A posicão em 'decúbito lạteral é impositiva para facilitar o escoamento do sangue, muco, excesso de saliva e evitar o risco da queda da língua. Nos casos de reconhecida anemia aguda, mantida a posição em decúbito lateral, os pés do ferido deverão estar em posição mais elevada que a cabeça. Os enfaixamentos crânio-mandibulares não se recomendam pelos problemas de asfixia que podem se apresentar. O transporte até a ambulância, como desta ao centro de atendimento, será em padiola ou maca o mais comum ou ambulando, o paciente deverá apoiar-se, cada mão em um ombro do enfermeiro ou transportador, fletindo a cabeça para a frente, pelas razões já expostas. Ainda a cadeira convencional poderá ser empregada, estando o paciente sentado com a cabeça fletida para a frente e os ante-braços apoiados às coxas, o tronco levemente inclinado. Esta posição será a adotar enquanto o paciente espera transporte.

$\mathrm{Na}$ segunda fase - Atendimento provisório hospitalar.

No centro primário de atendimento, às vêzes denominado sala de urgência, de primeiros socorros, de triagem ou que outra denominação tenha, serão prestados ao traumatizado os cuidados que o centro, com os recursos de tôda a ordem disponíveis o permitam:

a. realização de exames de rotina para estabelecimento do diagnóstico definitivo:

b. prevenção de complicações infecciosas de modo geral, inclusive do tétano;

c. hemostasia por sutura primária;

d. limpeza do paciente (a complementação da ferida será feita pelo cirurgião na sala);

e. troca da roupa do paciente (cuidados especiais devem ser dispensados para não agravar as lesões);

f. continuar a administração da medicação de emergência ou urgência.

Alguns casos, no entanto, considerando a gravidade dos traumas, são encaminhados diretamente à sala de intervenções, sem prévia substituicão da indumentária.

Os exames de rotina compreendem:

Antecedentes - causas e circunstâncias em que ocorreu o acidente (histórico), facilitará deduções para avaliação do dano e suas possíveis complicações.

Horário - sabendo-se a hora da ocorrência e da entrada no hospital, o número de horas decorridas entre a lesão e o atendimento propiciará dados valiosos, entre outros: a avaliação das condições de resistência física e moral do paciente; tipo de sutura a ser empregado (primária ou secundária, as feridas após 8 horas são consideradas infectadas ou mais sujeitas a infecção). A hemorragia mesmo que filiforme terá maior ou menor repercussão em decorrência do tempo decorrido e os cuidados variarão em razão dos problemas psi- 
quicos. O prognóstico em traumatirados graves sem atendimento por iongo tempo, será mais sombrio em tzualdade de condição com o pronramente atendido. Pulso e pressão arterial, indicação sôbre o estado do \#parelho circulatório. Temperatura e respiração - depõe sôbre estados infecciosos ou choque - hiper ou tipotermia. Problemas pulmonares, derrames pleurais e hipertensão intracraniana - bradicardia.

Exame geral - inspeção cuidadosa de todo o corpo em busca de outras lesões concorrentes, como equimoses, hematomas, deformações, fraturas ou luxações não observadas $r \in m$ suspeitadas anteriormente. Cuidado especial deve merecer a face.

Exame local - observação cuidadosa das lesões dos tecidos circunrizinhos. Inspeção bucal, dentes, mucosa, língua, assoalho da bôca e articulado dentário. A ATM e sua dinâmica deverá ser cuidadosamente observada, pois podemos colhêr informes sôbre fraturas em zonas desdentadas e que passam desapercebidas ou não referidas pelo paciente.

Exame de sangue - o sangue será colhido pelo laboratório para a hematimetria, dosagem de hemoglobina e hematócrito, que podem evidenciar hemoconcentração, anemia, etc. Determinacão do tipo sangüíneo e fator $\mathrm{RH}$, além de outros em cada caso particular.

Exame de urina - verificação de hematúria, levará a pensar em lesão renal ou de bexiga, com ou sem possível fratura da bacia.

Exame de líquor - nos casos de traumatismo ou suspeita de lesão craniana.

Exame radiológico -- a exploração deverá ser penorâmica e localizada no mínimo, em dues posições antagônicas, guiada sempre pelo diagnóstico clínico definitivo ou presuntivo. As lesões ósseas ou articulares, bem como problemas gerais, podem ser diagnosticados pelas radiografias, com ou sem contrastes, de acôrdo com o caso. A presença de corpos estranhos, bem como presença de lesões cavitárias podem ser evidenciadas. No diagnóstico, prognóstico, indicação terapêutica ou escolha de método ou técnica de tratamento pela identificação perfeita da fratura, bem como a avaliação clínica do tratamento, os Raios X têm grande indicação.

Na terceira fase - tratamento definitivo - a ação do traumatologista maxilo-facial terá início na sala cirúrgica, após o sinal verde para sua intervenção, aceso pelo neurologista, cirurgião ou clínico, conforme o caso e comportará ação no hospital de Pronto Socorro, hospital geral e ou ambulatório.

\section{SYYOPSIS}

A review about general care, clonical examinations, laboratories test and transportation care of wounded platients with poly traumatism. 


\section{REFERÊNCIAS BIBLIOGRÁFICAS}

1. ACKERMANN, R. - L'urgence en odonto-stomatologie. Paris, Masson \& Julien Prélat, 1964. 419p.

2. ALVES, Emmanuel - Cirurgia de urgência. 3.ed. Rio de Janeiro, Atheneu, 1957. 2v.

3. AULETE, Caldas. Dicionário contemporâneo da língua portuguêsa. 4. ed. Rio de Janeiro, Delta, 1968. 5v.

4. BERLOVE, Ira Jay - Dental-medical; emergencies and coplications. - Chicago, Year Book, 1963. 491p.

5. BRANDÃ், Gaspar Soares - Introdução ao estudo da Traumatologia Bucofacial. Opúsculo, Rio, 1956. 16p.

6. DOUglas, Bruce L. - A guide to hospital dental procedure. Chicago, A.D.A. 1964. 195p.

7. DILLE, James M. - Drug therapy for dentists; with a special section on «dental emergencies». Chicago, Year Book Medical Publ., 1963. 228p.

8. FRY, W. K. et alii - The dental treatment of maxillo facial injuries. Philadelphia, Lippincott. (s. d.) $434 \mathrm{p}$.

9. GRAZIANI, Mário - Fraturas mandibulares; civis e de guerra. São Paulo, Ponzini, 1944. 271p.

10. LASKIN, Daniel M. - Management of oral emergencies. Springfield, Charles C. Thomas, 1964. 107p.

11. NOGUEIRA, Dirsa - Tratamento de urgência na fratura da face. Rev. da Fac. de Odontologia Pôrto Alegre, 3:115-129, 1961.

12. ROMEIRo, Vieira - Medicina de urgência. 3.ed. Rio de Janeiro, Guanabara, 1960. 2v.

13. THOMA, Kurt H. - Traumatic surgery of the jaws; including firstaid treatment. St. Louis, Mosby, 1942. 315p. 